\title{
EVALUACIÓN DE LOS MÉTODOS DE REGENERACIÓN APLICADOS EN EL TIPO FORESTAL ROBLE - HUALO EN LA REGIÓN DEL MAULE
}

Iván Quiroz M. ${ }^{1}$, Edison García R. ${ }^{1}$ Marta González $\mathrm{O}^{1}$. y Hernán Soto G. ${ }^{1}$

\section{RESUMEN}

El presente trabajo corresponde a una línea de investigación encargada a INFOR por el Ministerio de Agricultura y contiene la metodología aplicada y los resultados obtenidos en la evaluación de los métodos de regeneración para el Tipo Forestal Roble - Hualo. Se evaluaron áreas representativas e intervenidas en los últimos 20 años en la Región del Maule, con el objetivo de generar y sistematizar antecedentes técnicos sobre la aplicabilidad de los métodos de regeneración para este tipo forestal..

La literatura técnica sobre el tema, nacional e internacional (Norteamérica y Europa), muestran procedimientos silviculturales que son utilizados en bosques de estructura simple (número de especies) y equilibrados. Sin embargo, en Chile los bosques nativos se caracterizan por su alta heterogeneidad, en cuanto a la distribución y calidad de los individuos, a ello se suma que son bosque compuestos por diferentes especies, que han sido intervenidos sin consideraciones de tipo silvícola, generando masas boscosas que requieren variados métodos silviculturales para lograr su equilibrio en cuanto a estructura vegetacional y calidad maderera y no maderera (hongos comestibles, frutos, otros).

Se reconoce que la forma en que se aplican los actuales métodos de regeneración no contribuyen a mejorar la calidad de los bosques y así mismo que los esquemas preestablecidos en la normativa vigente al respecto no se adecúan a su actual composición y desarrollo, por ello es necesario incorporar criterios de manejo (o regeneración) que representen las diferentes condiciones del bosque.

Palabras clave: Bosque nativo, manejo forestal, Tipo Forestal Roble - Hualo

1 Instituto Forestal, Sede Bio Bio, Concepción - Centro Tecnológico de la Planta Forestal, Chile. ivan.quiroz@infor. $\mathrm{cl}$ 


\section{SUMMARY}

This paper is under the framework of a research line on native forest management supported by the Agriculture Ministry and contains the methodology and the results of regenerative methods applied to the Roble - Hualo forest type. Representative areas intervened during the last 20 years in Maule's Region were evaluated with the objective of generating and systematizing technical background on the applicability of the regeneration methods for this forest type.

National and international (North America and Europe) technical references on the matter mention different silvicultural procedures used in simple structure (number of species) and balanced forests. However, the Chilean native forests are characterized by a high heterogeneity in the distribution and quality of individuals and a number of species their composition, and have been intervened in the past without silvicultural considerations. Consequently, those forests nowadays require silvicultural methods to achieve a balance in terms of the vegetation structure and the quality of wood and non-wood forest products (mushrooms, fruits, others).

It is recognized that the current applied regeneration methods are not contributing to improve the forests quality and the technical practices established on the regulations in force on the matter are not appropriated to their present composition and development. That is the reason why it is necessary the application of management (or regeneration) criteria accordingly to the different current native forest conditions.

Key words: Native forests, forest management, Roble - Hualo Forest Type 


\section{INTRODUCCIÓN}

En el año 1974 se promulga el Decreto Ley № 701 con la finalidad de regular el uso racional de los recursos naturales renovables de los terrenos forestales y en general propender a la conservación, mejoramiento, protección e incremento de estos recursos en el país.

Para el bosque nativo se generó además el Reglamento Técnico DS № 259/1980, que regula su manejo de modo de asegurar la regeneración, reconociendo para esto los métodos de corta a Tala Rasa, Árbol Semillero, de Protección y Selectiva o Entresaca.

Esta normativa ha tenido por objetivo velar por la sustentabilidad del bosque nativo, es decir, que se obtengan productos de calidad en forma continua, sin embargo, son numerosos los estudios que demuestran la descapitalización económica por pérdidas de cantidad, calidad y estructura del recurso como resultado de su sobreutilización.

Actualmente los bosques nativos presentan diferentes grados de intervención y degradación y, dependiendo de la calidad original del bosque y de la frecuencia con que fue intervenido, el rodal resultante es más o menos abierto con una escasa regeneración a consecuencia del fuerte desarrollo del sotobosque.

Un esfuerzo adicional por asegurar la sustentabilidad del bosque es la aprobación de la Ley $N^{\circ}$ 20.283/2008 (CONAF, 2010a), de Recuperación del Bosque Nativo y Fomento Forestal, para cuya implementación se han aprobado sus Reglamentos General y Específicos, y se está por concretar prontamente el Reglamento de Suelo, Aguas y Humedales.

En esta Ley se indica, en su Título I De los Tipos Forestales, que "mediante decreto supremo expedido por intermedio del Ministerio de Agricultura, se establecerán los tipos forestales a que los pertenecen los bosques nativos del país y los métodos de regeneración aplicables a ellos". En la misma ley se indica que "El procedimiento para establecer los tipos forestales y los métodos de regeneración considerará, a lo menos, las siguientes etapas: Desarrollo de estudios científicos y técnicos que fundamenten la tipología establecida, sus métodos de regeneración y consulta a los organismos públicos y privados con competencia en la materia".

El presente documento fue desarrollado por el Instituto Forestal como parte de los estudios sobre bosque nativo encargados por el Ministerio de Agricultura. Contiene la metodología aplicada y los resultados obtenidos en la evaluación de los sistemas silviculturales (métodos de regeneración) aplicados al tipo forestal Roble - Hualo. Fueron evaluadas áreas representativas e intervenidas en los últimos 20 años, y el trabajo tiene por objetivo generar y sistematizar antecedentes técnicos sobre la aplicabilidad de los métodos de regeneración al tipo forestal Roble - Hualo en la Región del Maule. 


\section{CARACTERIZACIÓN TIPO FORESTAL ROBLE - HUALO}

El Tipo Forestal Roble-Hualo se distribuye en gran parte de la región de clima mediterráneo del país, por ambas cordilleras. En la Cordillera de la Costa se encuentra en

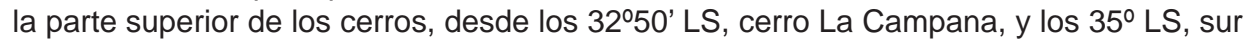
del río Mataquito, hasta el río Itata en los 3630' LS. Dependiendo de la latitud, este tipo limita en las partes bajas de las laderas con el Tipo Forestal Esclerófilo. En la Cordillera

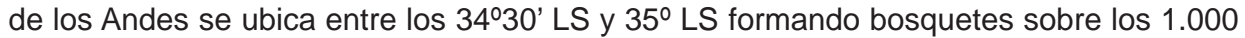
m de altitud. Al sur de los 35 LS y hasta los 3650' LS, río Ñuble, los bosques crecen en forma aproximadamente continua sobre los 400 a $600 \mathrm{msnm}$ (Donoso, 1981).

Desde un punto de vista florístico y estructural, este tipo forestal incluye 5 subtipos dentro de su distribución:

Subtipo bosquetes costeros septentrionales de roble (Nothofagus obliqua (Mirb.) Oerst.)

Subtipo bosques andinos de roble de altura

Subtipo bosques de hualo (Nothofagus glauca (Phil.) Krasser)

Subtipo bosquetes de ruil (Nothofagus alessandrii Espinosa)

Subtipo Bosques higrófitos de quebradas

Dentro del área de distribución de este tipo forestal, las altitudes menores en la precordillera de los Andes han sido alteradas en general y transformadas en campos agrícolas. En la cordillera de la Costa, en el límite norte hasta el río Mataquito, este tipo se presenta como bosquetes aislados en las cumbres y laderas o quebradas altas húmedas.

En las elevadas cumbres entre Santiago y Valparaíso los bosquetes son rodales casi puros de roble; se asocian con esta especie peumo (Cryptocarya alba (Mol.) Looser), maitén (Maytenus boaria Mol.), quillay (Quillaja saponaria Mol.) y litre (Lithraea caustica (Molina) Hook. et Arn). Al sur de estos cordones aparece hualo formando bosquetes aislados que no se mezclan con los de roble, estos últimos crecen en esta área en las quebradas y sectores más húmedos.

Al sur del río Mataquito y hasta el río Itata por la cordillera de la Costa el bosque aparece en forma continua y la especie de mayor importancia relativa pasa a ser hualo o roble colorado, que constituye bosques casi puros en las laderas de los cerros. El sotobosque está constituido por algunos ejemplares de lingue (Persea lingue Ness), radal (Lomatia hirsuta (Lam.) Diels ex MacBride), avellano (Gevuina avellana Mol.), peumo, boldo (Peumus boldus (Molina) Johnnston) y litre.

En algunas laderas de exposición Sur Oeste, dentro de estos sectores, se encuentran rodales de ruil. En las quebradas y terrenos húmedos, en general, se 
desarrollan bosques de tipo más higrófito, donde las especies de mayor importancia son roble o hualle, canelo (Drymis winteri J.R. et G. Forster.), olivillo (Aextoxicon punctatum R. et Pav.), lingue, huala (Nothofagus leonii Espinosa) y otras.

En la cordillera de los Andes el tipo se caracteriza por la mayor importancia relativa de roble en los bosquetes y bosques del sector septentrional desde el límite norte hasta el río Lontué, en los sectores sobre los 1.000 msnm, al sur del río Maule.

Al sur del río Lontué, en las áreas bajas, en las exposiciones sur y lomajes sobre los $1.000 \mathrm{msnm}$, roble forma bosques puros, pero en las exposiciones más cálidas, hualo es la especie de mayor importancia, formando bosques prácticamente puros (Donoso, 1981).

Históricamente el Tipo Forestal Roble-Hualo ha sufrido una severa intervención antrópica, primero para habilitar terrenos para asentamientos humanos, luego para ser reemplazados por cultivos agrícolas y posteriormente para el cultivo de especies forestales exóticas. Como resultado de lo anterior, lo que en el pasado fue una gran extensión continua de bosques, actualmente esta reducido a pequeños parches 0 fragmentos, aislados entre sí, lo que los hace vulnerables a la acción invasora de la matriz que los circunda. La acción conjunta de estos factores se conoce como fragmentación (Donoso, 1994).

De acuerdo al catastro vegetacional de las especies nativas de Chile (CONAFCONAMA-BIRF, 1999), la superficie total de Bosque Nativo en el país es de 13.430 .603 ha, de ella la superficie total del tipo forestal Roble - Hualo es de 187.586 ha $(1,4 \%)$, distribuidas entre las regiones de Valparaíso y del Bio Bio. La mayor concentración se observa en la Región del Maule, con una superficie aproximada de 148.182 ha, $79 \%$ del total del tipo forestal y $40 \%$ del total de bosque nativo regional. 


\section{Cuadro $\mathrm{N}^{\circ} 1$ \\ SUPERFICIE REGIONAL Y PROVINCIAL DEL TIPO FORESTAL ROBLE-HUALO SEGÚN ESTRUCTURA}

\begin{tabular}{|c|c|c|c|c|c|}
\hline \multirow{2}{*}{ REGIÓN/ PROVINCIA } & ADULTO & RENOVAL & ADULTO-RENOVAL & ACHAPARRADO & TOTAL \\
\cline { 2 - 6 } & \multicolumn{5}{|c|}{$\begin{array}{c}\text { SUPEBACIE } \\
\text { (ha) }\end{array}$} \\
\hline
\end{tabular}

\begin{tabular}{|c|c|c|c|c|c|}
\hline VALPARAISO & & & & & \\
\hline Petorca & - & - & - & - & 0,0 \\
\hline San Felipe & - & 149,9 & - & - & 149,9 \\
\hline Quillota & - & 429,2 & - & - & 429,2 \\
\hline Los Andes & - & - & - & - & 0,0 \\
\hline Valparaíso & - & 53,7 & - & - & 53,7 \\
\hline Total Región & 0,0 & 632,8 & 0,0 & 0,0 & 632,8 \\
\hline Porcentaje Región (\%) & 0,0 & 100,0 & 0,0 & 0,0 & \\
\hline
\end{tabular}

\begin{tabular}{|c|c|c|c|c|c|}
\hline METROPOLITANA & & & & & \\
\hline Chacabuco & - & 840,9 & - & - & 840,9 \\
\hline Santiago & - & - & - & - & 0,0 \\
\hline Cordillera & - & - & - & - & 0,0 \\
\hline Melipilla & - & $4.967,4$ & -1 & - & $4.967,4$ \\
\hline Total Región & 0,0 & $5.808,3$ & 0,0 & 0,0 & $5.808,3$ \\
\hline Porcentaje Región (\%) & 0,0 & 100,0 & 0,0 & 0,0 & \\
\hline
\end{tabular}

\begin{tabular}{|c|c|c|c|c|c|}
\hline O'HIGGINS & & & & & \\
\hline Cardenal Caro & - & - & - & - & 0,0 \\
\hline Cachapoal & - & $3.162,6$ & - & - & $3.162,6$ \\
\hline Colchagua & $1.461,1$ & $11.128,8$ & $2.549,4$ & - & $15.139,3$ \\
\hline Total Región & $1.461,1$ & $14.291,4$ & $2.549,4$ & 0,0 & $18.301,9$ \\
\hline Porcentaje Región (\%) & 8,0 & 78,1 & 13,9 & 0,0 & \\
\hline
\end{tabular}

\begin{tabular}{|c|c|c|c|c|c|}
\hline MAULE & & & & & \\
\hline Curicó & - & $1.846,0$ & 593,0 & - & $2.439,0$ \\
\hline Talca & - & $26.120,0$ & 552,0 & - & $26.672,0$ \\
\hline Cauquenes & - & $11.814,0$ & 547,0 & - & $12.361,0$ \\
\hline Linares & $7.463,0$ & $88.581,0$ & $10.666,0$ & - & $106.710,0$ \\
\hline Total Región & $7.463,0$ & $128.361,0$ & $12.358,0$ & 0,0 & $148.182,0$ \\
\hline Porcentaje Región (\%) & 5,0 & 86,6 & 8,3 & 0,0 & \\
\hline
\end{tabular}

\begin{tabular}{|c|c|c|c|c|c|}
\hline BIO BIO & & & & & \\
\hline Ñuble & $1.641,8$ & $9.987,5$ & $3.031,9$ & -1 & $14.661,2$ \\
\hline Concepción & & & $\therefore$ & -1 & 0,0 \\
\hline Arauco & -1 & -1 & -1 & -1 & 0,0 \\
\hline Bío - Bío & -1 & - & - & - & 0,0 \\
\hline Total Región & $1.641,8$ & $9.987,5$ & $3.031,9$ & 0,0 & $14.661,2$ \\
\hline Porcentaje Región (\%) & 11,2 & 68,1 & 20,7 & 0,0 & \\
\hline TOTAL TIPO & $10.565,9$ & $159.081,0$ & $17.939,3$ & 0,0 & $187.586,2$ \\
\hline PORCENTAJE (\%) & 5,6 & 84,8 & 9,6 & 0,0 & \\
\hline
\end{tabular}

En la Región del Libertador del General Bernardo O’Higgins, de las 118.013 ha de bosque nativo, el 15,5 \% corresponde al Tipo Forestal Roble-Hualo; en la región 
Metropolitana, cuyo recurso alcanza las 93.454 ha, alrededor del $7 \%$; en la Región del Biobío, de las 785.766 ha, sólo el 1,9 \%; y, en la Región de Valparaíso, de 95.312,9 ha de bosque nativo, un escaso $0,7 \%$.

Es importante indicar que tradicionalmente la forma de explotación de los bosques nativos ha sido el floreo, sin conocimiento de las mejores técnicas silviculturales y de manejo que aseguren la sustentabilidad del recurso, razón por la cual el $84,8 \%$ de la superficie del tipo forestal Roble - Hualo a nivel nacional se encuentra en estado de renoval, con un alto grado de intervención (Cuadro $N^{\circ} 1$ ).

\section{Tratamientos Silviculturales para Favorecer la Regeneración}

En el año 1980, se generó el Reglamento Técnico DS N²59/1980, que regula el manejo del bosque nativo de modo de asegurar su regeneración. Para ello, establece como métodos de corta: Corta a tala rasa, corta del árbol semillero, corta de protección y corta selectiva o entresaca. Asimismo, en éste reglamento se reconocen 12 tipos forestales, para los cuales se norman distintos métodos de corta y restricciones específicas, no obstante, solo en 10 se permiten intervenciones forestales.

Según este Reglamento el tipo forestal Roble-Hualo, es aquél que se encuentra representado por la presencia de una o ambas especies, roble y/o hualo, constituyendo, a lo menos, un 50 \% de los individuos por hectárea, permitiéndose la aplicación de los 4 tratamientos silviculturales o métodos de corta y regeneración mencionados anteriormente, y que consisten básicamente en:

Corta o explotación a tala rasa: El volteo en una temporada de todos los árboles de un área definida del rodal. En este caso deberá establecerse un mínimo de 3.000 plantas por hectárea de las mismas especies homogéneamente distribuidas.

Corta o explotación por el método del árbol semillero: El volteo de todos los árboles del rodal en una temporada, exceptuando los árboles semilleros dejados para repoblar el área, los que serán de la especie que se desee regenerar. En este caso deberá dejarse como mínimo 10 árboles semilleros por hectárea, que permanecerán en pie hasta la fecha en que se establezcan, a lo menos, 3.000 plantas por hectárea, de la misma especie, homogéneamente distribuidas.

Corta o explotación de protección: La explotación gradual de rodal en una serie de cortas parciales, para dar origen a un rodal coetáneo a través de regeneración natural la cual se inicia bajo la protección del antiguo rodal. El propietario deberá establecer 3.000 plantas por hectárea como mínimo, de las mismas especies cortadas del tipo, homogéneamente distribuidas.

Corta o explotación selectiva o entresaca: La extracción individual de árboles o de pequeños grupos en una superficie no superior a 0,3 ha, debiendo mantenerse en este caso una faja boscosa alrededor de lo cortado de a lo menos 50 m. Mediante este método, solamente podrá extraerse hasta el $35 \%$ del área basal del rodal, debiendo establecerse como mínimo 10 plantas de la misma especie por cada 
individuo cortado, o 3.000 plantas por hectárea del tipo correspondiente, en ambos casos homogéneamente distribuidos. Una nueva corta selectiva en el mismo rodal, solamente se podrá efectuar una vez transcurrido 5 años desde la corta anterior.

Cuando el bosque se encontrare en terrenos de una pendiente mayor de $45 \%$ no se podrán usar los métodos de tala rasa o de árbol semillero. Si la pendiente fuere entre $30 \%$ y $45 \%$ y se usare el método de la tala rasa o del árbol semillero, los sectores a cortar no podrán exceder de una superficie de 20 ha, debiendo dejarse entre sectores una faja boscosa de, a lo menos, $100 \mathrm{~m}$. En pendientes superiores a $60 \%$ sólo podrá usarse el método de corta o explotación selectiva.

\section{Cuadro $\mathrm{N}^{\circ} 2$ \\ MÉTODO DE CORTA SEGÚN TIPO FORESTAL Y RESTRICCIONES POR PENDIENTE}

\begin{tabular}{|c|c|c|c|c|c|c|c|c|c|c|c|c|}
\hline \multirow{4}{*}{$\begin{array}{c}\text { TIPO } \\
\text { FORESTAL }\end{array}$} & \multicolumn{12}{|c|}{ METODOS DE REGENERACIÓN } \\
\hline & \multicolumn{3}{|c|}{ Tala Rasa } & \multicolumn{3}{|c|}{ Árbol Semillero } & \multicolumn{3}{|c|}{$\begin{array}{c}\text { Corta de } \\
\text { Protección } \\
\end{array}$} & \multicolumn{3}{|c|}{ Corta Selectiva } \\
\hline & \multicolumn{12}{|c|}{$\begin{array}{c}\text { Pendiente } \\
(\%)\end{array}$} \\
\hline & $<45$ & $45-60$ & $>60$ & $<45$ & $45-60$ & $>60$ & $<45$ & $45-60$ & $>60$ & $<45$ & $45-60$ & $>60$ \\
\hline Siempreverde & & & & & & & $x$ & $x$ & & $x$ & $x$ & $x$ \\
\hline Lenga & & & & & & & $x$ & $x$ & & $x$ & $x$ & $x$ \\
\hline Roble-Rauli-Coigüe & $x$ & & & $\mathrm{x}$ & & & $x$ & $x$ & & $x$ & $x$ & $x$ \\
\hline Coigüe-Raulí-Tepa & & & & $x$ & & & $x$ & $x$ & & $x$ & $x$ & $x$ \\
\hline Esclerófilo & & & & & & & $x$ & $x$ & & $x$ & $x$ & $x$ \\
\hline Coigüe Magallanes & & & & & & & $x$ & $x$ & & $x$ & $x$ & $x$ \\
\hline Ciprés Guaitecas & & & & & & & & & & $x$ & $x$ & $x$ \\
\hline Roble - Hualo & $\mathrm{x}$ & & & $x$ & & & $x$ & $x$ & & $x$ & $x$ & $x$ \\
\hline Ciprés Cordillera & & & & & & & $x$ & $x$ & & $x$ & $x$ & $x$ \\
\hline Palma chilena & & & & & & & & & & $x$ & $x$ & $x$ \\
\hline Araucaria & \multicolumn{12}{|c|}{ Prohibida su corta. } \\
\hline Alerce & \multicolumn{12}{|c|}{ Prohibida su corta. } \\
\hline
\end{tabular}

(Fuente: FIA, 2001).

Lenga (Nothofagus pumilio (Poepp et Lendl.) Krasser), Raulí (Nothofagus nervosa (Phil.) Dim. et Mil.), Coigüe (Nothofagus dombeyi (Mirb.) Oerst), Tepa (Laureliopsis philippiana Looser), Coigüe de magallanes (Nothofagus betuloides (Mirb.) Oerst.), Ciprés de las guaitecas (Pilgerodendron uviferum (D.Don) Florin), Ciprés de la Cordillera (Austrocedrus chilensis (D. Don) P.Sem.et Bizarri), Palma chilena (Jubaea chilensis (Mol.) Baillon), Araucaria (Araucaria araucana (Mol.) K.Koch.), Alerce (Fitzroya cupressoides (I.M.) Johnst.) 


\section{Superficie Intervenida del Tipo Forestal Roble-Hualo}

Durante los últimos 30 años la superficie intervenida en el Tipo Forestal Roble - Hualo en las regiones de O'Higgins a Biobío, alcanza a 53.359 ha, involucrando aproximadamente a 890 predios, con una superficie media por predio de 60 ha.

De acuerdo con los registros de los planes de manejo, para este tipo forestal se observan tres ciclos de intervención (CONAF 2010 b). El primero considera el periodo desde 1980 a 1985 con una alta participación en términos de superficie. En iguales condiciones, el segundo período se inicia el año 1988 y finaliza el año 1995 con casi 2.000 ha afectadas, periodo que se caracterizó además por cierto dinamismo de la actividad forestal en el bosque nativo, coincidiendo con el "negocio de la astillas" donde se extrajeron y exportaron entre el año 1991 y 1997 más de 2.000 .000 t de astillas en promedio (INFOR, 2009). Posterior al año 1995, se ha observado una baja considerable de superficie intervenida, la que ya ha fines de 2009 llegó a tan solo 240 ha (Figura $N^{\circ}$ 1).

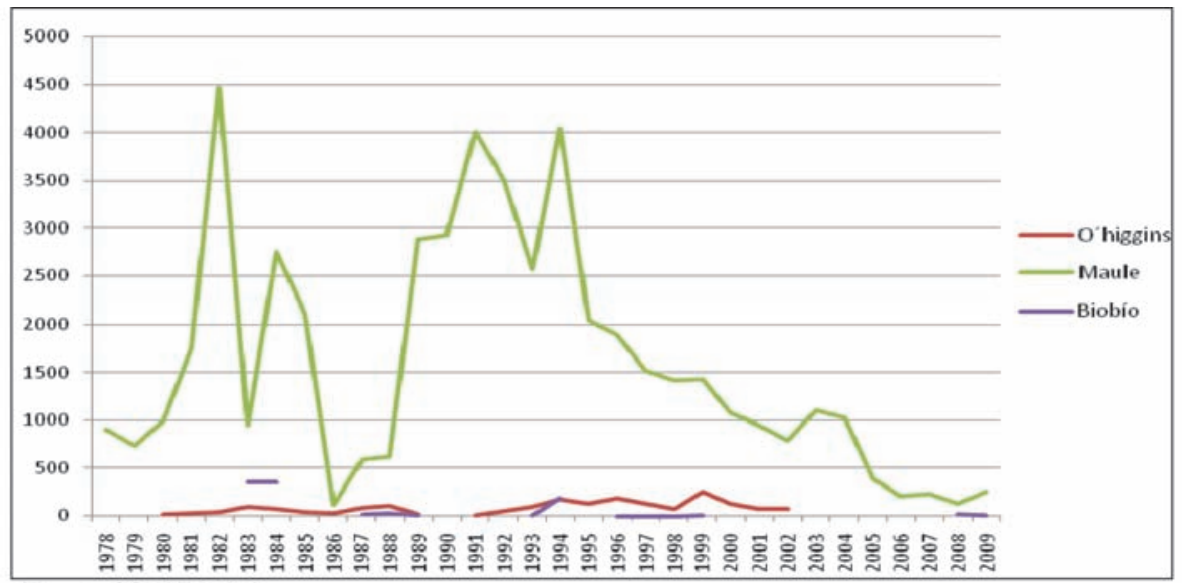

(Fuente: CONAF, 2010).

Figura $\mathrm{N}^{\circ} 1$

SUPERFICIE TOTAL DE BOSQUE INTERVENIDOS DEL TIPO FORESTAL ROBLE-HUALO REGIONES DE O’HIGGINS A BIOBÍO

(hectáreas)

La Región del Maule presenta la mayor superficie intervenida del Tipo Forestal Roble - Hualo, con un total desde el año 1978 al 2009 de 50.414 ha, lo que representa el $94 \%$ de la superficie total manejada entre las regiones de O’higgins a Biobío.

Según los antecedentes, mayoritarimente los métodos aplicados a nivel nacional fueron cortas de liberación, plantaciones, métodos silvícolas que favorecen la regeneración natural y otros, equivalente al $34 \%$ del total de la superficie intervenida. Le siguen las 
cortas selectivas, que alcanzan el $26 \%$ del bosque manejadoy los raleos con un 17 $\%$ de participación. Al analizar los métodos de regeneración en especifico, el de mayor importancia es la corta selectiva. con 14.182 ha, le sigue la corta de protección con 5.859 hectareas, y finalmente el método del árbol semillero con 2.177 ha (Figura $N^{\circ} 2$ ).

Cuando se analiza el comportamiento de las intervenciones a nivel regional, se aprecian variaciones porcentuales significativas entre las regiones de Bio Bio y Maule, por ejemplo, de la superficie intervenida en Bio Bio, un alto porcentaje corresponde al método del árbol semillero, corta selectiva y raleos, no obstante en Maule, el mayor porcentaje de superficie intervenida corresponde a otros métodos, corta selectiva y raleos. En la región de O'higgins el mayor porcentaje de superficie intrevenida corresponde a corta selectiva y otros métodos. Cabe señalar que una alta participación porcentual a nivel regional por tipo de intervención son las cortas selectivas (Figura № 2).

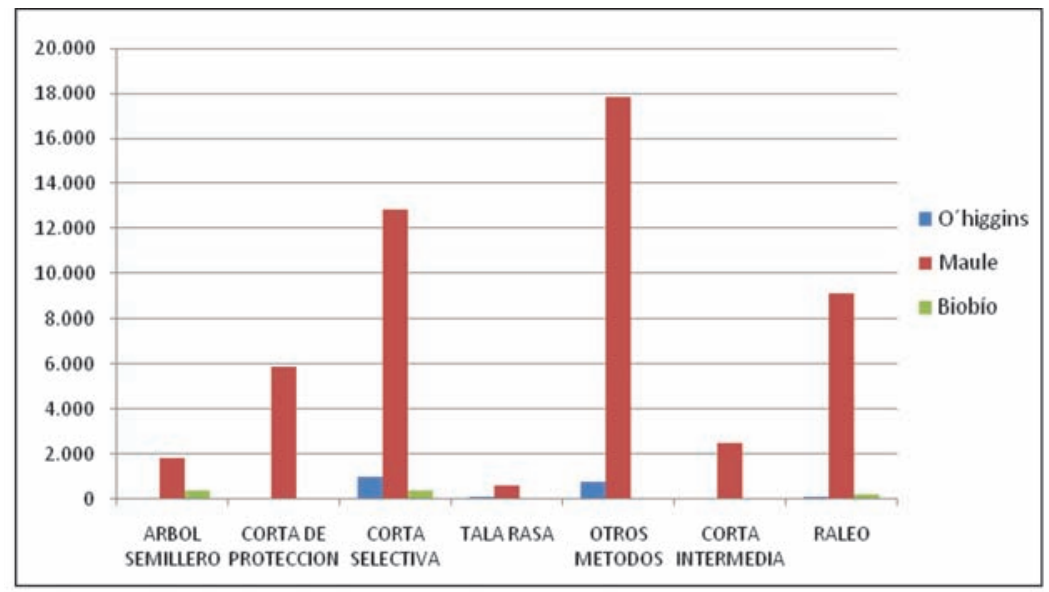

Figura $\mathrm{N}^{\circ} 2$

SUPERFICIE TOTAL INTERVENIDA SILVÍCOLAMENTE DEL TIPO ROBLE - HUALO PERIODO 1978-2009, POR REGIONES Y SEGÚN TIPO DE INVENCIÓN

\section{MATERIAL Y METODO}

\section{Caracterización de los Predios}

Para la caracterización de los predios se emplearon bases de datos proporcionadas por la Corporación Nacional Forestal (CONAF), apoyados con imágenes de satélite y cartas IGM. Con estos antecedentes se localizaron en oficina predios con presencia de Roble-Hualo en sus coordenadas UTM en X e Y, considerando la variación de Huso 18 a Huso 19 y Datum WGS 84. Con esta información se realizaron las evaluaciones de terreno, donde se registraron las siguientes variables:

Ubicación administrativa: Esto incluye Comuna, nombre del predio, número de 
rol SII, nombre del propietario, nombre de contacto, teléfono fijo o celular, superficie total del predio, superficie del rodal(es) intervenido(s), otros de interés.

Pendiente: El cálculo de la pendiente permite establecer con precisión la parcela. Para ello se identifica en terreno, y sobre el punto centro de la parcela, la dirección de la pendiente más pronunciada (dirección de la pendiente predominante). Para su determinación se utilizaron instrumentos de precisión y a una distancia de 30 metros. Posteriormente, se clasificaron de acuerdo con lo siguiente:

Código 1 para rango de pendiente entre 0 y $15 \%$.

Código 2 para el rango de pendiente entre 16 a $30 \%$.

Código 3 para el rango de pendiente entre 31 a $45 \%$.

Exposición: Disposición principal del terreno intervenido en relación a los puntos cardinales (N: Norte; S: Sur; E: Este; O: Oeste; NE: Noreste; SE: Sureste; NO: Noroeste; SO: Suroeste), para cada situación encontrada en terreno.

Altitud: Indicada en metros sobre el nivel del mar según lo indicado por los instrumentos de precisión (GPS).

Punto de georeferencia: La ubicación del predio en coordenadas UTM y tipo de Huso (GPS).

Tipo de bosque:

Monte Alto: Los individuos del bosque se han originado desde semilla.

Monte Bajo: $\quad$ Los árboles del bosque se han originado mediante reproducción vegetativa, ya sea por brotes de tocón o de raíces.

Monte Medio: Los árboles de la parcela presentan un tipo mixto, algunos se han desarrollado de tocones y otros de semilla.

Observaciones generales de acceso y llegada al predio: Identificación de los caminos más cercanos que llegan a la parcela.

\section{Tamaño y Distribución de la Unidad Muestral}

El levantamiento de la información relevante se obtuvo de la unidad muestral de caracterización conformada por tres parcelas circulares de diferentes tamaños:

Parcela de Árboles Residuales: Se definen como parcelas circulares de radio 12,62 m (500 $\left.\mathrm{m}^{2}\right)$, con un mínimo de 3 parcelas por rodal intervenido y según sistema de regeneración utilizado. La distribución de estas parcelas se determinó en gabinete y se evalúan todas las especies de un diámetro (DAP) superior a 8 $\mathrm{cm}$. 
Parcelas de Regeneración Artificial: Esta parcela tiene un radio de 6,25 m (123 $\mathrm{m}^{2}$ ) y se evalúan todas las plantas establecidas, sin restricciones de desarrollo.

Parcelas de Regeneración Natural: En esta parcela de radio de 1,13 m (4 m²) se evalúan todas las especies regeneradas presentes dentro de la parcela.

Por cada parcela de bosque residual se evaluaron 3 parcelas de regeneración artificial y 3 parcelas de regeneración natural distribuidas de norte a sur y en forma equidistante.

La ubicación de la unidad muestral se determinó en oficina, mediante una secuencia de localización de la primera parcela en el centro del rodal y las siguientes equidistantes a ella en orientación $\mathrm{E}$ y $\mathrm{O}$ de manera sistemática. Una vez en terreno, si las condiciones del predio, en cuanto a forma y/o ubicación espacial, no permitían lo anterior, las parcelas se ubicaron bajo una nueva orientación desde el centro de la parcela, y de acuerdo al siguiente orden: NO-SE, NE-SO y N-S, hasta completar el número de parcelas determinadas por el método de regeneración aplicado para la superficie del predio.

El número de la unidad muestral por método de regeneración y predio se definieron en relación con la superficie intervenida, estableciendo tres rangos, correspondiendo por tramo el siguiente número de unidades muestrales:

Superficies menores a 15 ha: 3 unidades muestrales de caracterización.

Superficies ubicadas en el rango entre 15 y 30 ha: 4 unidades muestrales de caracterización.

Superficies mayores a 30 ha: 5 unidades muestrales de caracterización.

Se determinó una superficie mínima intervenida para evaluación de 3 ha, superficie que permite establecer un mínimo de 3 parcelas de bosque residual de $500 \mathrm{~m}^{2}$. Los criterios de las correcciones de las parcelas y bordes se encuentran descritos en Quiroz et al., 2010.

\section{Caracterización del Bosque Residual}

\section{- Variables de Rodal}

Cobertura de copa para el rodal (\%): Valor aproximado en porcentaje, de cobertura clasificándolas de acuerdo a los siguientes rangos.

1: Cobertura de menos del $25 \%$

2: Cobertura entre el 25 y $50 \%$

3: Cobertura entre el 50 y $75 \%$

4: Cobertura entre el 75 y $100 \%$

Especie: Indica nombre de especies presentes en el rodal y sujetas a medición. 
Diámetro a la altura de pecho (DAP en $\mathbf{c m}$ ): Registro de todos los árboles mayores o iguales a $8 \mathrm{~cm}$ de diámetro. Por convención el Diámetro a la altura del pecho (DAP) es el diámetro del árbol medido a 1,3 m de altura desde el suelo. Para su medición se utilizó huincha diamétrica. Para la evaluación del DAP $(\mathrm{cm})$ se consideró lo establecido por Zöhrer (1980).

La forma de medir el DAP también depende de la inclinación que pueda presentar el árbol y su posición en pendiente respecto del observador. Otros casos especiales son los de forma, donde se pueden podemos encontrar bifurcaciones del tronco, o la presencia en algunos árboles, de los llamados contrafuertes.

Altura total $(\mathrm{m})$ : Se mide en al menos los siete árboles más centrales pertenecientes a la posición sociológica dominante y co-dominante.

Altura de inicio de copa (m): Altura de inicio de la copa viva del árbol.

Posición sociológica: Para esta clasificación, se debe considerar lo indicado en la Quiroz et al., 2010.

Tocones: Se miden todos los tocones de la parcela, numerándoles, indicando si es posible, la especie y midiendo su diámetro $(\mathrm{cm})$.

- Regeneración Artificial

Para la regeneración artificial se registraron los siguientes parámetros:

Especie: Nombre de la especie establecida.

Altura: Altura de todas las plantas establecidas en el interior de la parcela (m).

Diámetro altura del cuello DAC: Diámetro a la altura de cuello de la planta medido a $1 \mathrm{~cm}$ desde el suelo $(\mathrm{cm})$.

Diámetro a la altura de pecho DAP: Diámetro a la altura de pecho de las plantas medido a 1,3 $\mathrm{m}$ si corresponde $(\mathrm{cm})$.

Calidad de la planta: Se evaluó de acuerdo a las siguientes categorías.

1: Alta vitalidad con crecimiento normal. Ápice y follaje saludables.

2: Ápice y follaje dañado, pero que no compromete su supervivencia.

3: Ápice y follaje dañado o muerto, y compromete su supervivencia.

4: Muerta.

Observaciones: Se señalan las especies arbustivas y herbáceas observadas en la parcela. 


\section{- Regeneración Natural}

La regeneración o las variables asociadas a ella permiten estimar cuál será la composición y calidad de los bosques futuros, las acciones a realizar que permitan contar con mayor número de futuras plantas de ciertas especies de interés, o bien los tratamientos silviculturales que permitan favorecer la presencia de regeneración. En este caso, las variables medidas fueron:

Especie: Se registra el nombre de la especie o especies presentes.

Tipo de Regeneración: 1: Vegetativa; 2: Generativa

Clasificación por rango de altura $(\mathrm{m})$ y número de plantas por rango: Se clasificaron todas las especies con un diámetro menor a $8 \mathrm{~cm}$ y número de plantas en los siguientes rangos: $0,0-0,5 ; 0,5-1,0 ; 1,0-2,0$ y $>2,0 \mathrm{~m}$.

\section{Calidad de la regeneración natural clasificada en:}

1: Alta vitalidad con crecimiento normal. Ápice y follaje saludables.

2: Ápice y follaje dañado, pero que no compromete su supervivencia.

3: Ápice y follaje dañado o muerto, y compromete su supervivencia.

Observaciones: Se registra en términos generales la situación actual de la regeneración observada por tipo.

\section{DISCUSIÓN Y RESULTADOS}

Los rodales evaluados se distribuyen desde la comuna de San Clemente hasta Parral por la Precodillera de los Andes y, entre Pelluhue y Cauquenes por la Cordillera de la Costa, a una altitud entre los 400 a $1.000 \mathrm{msnm}$. Se presentan en exposiciones Norte a Nor-Oeste y en general en pendientes inferiores a $45 \%$ (Cuadro $N^{\circ} 3$ ), en su mayoría en estado de dasarrollo de latizal a fustal delgado con poco desarrollo de la vegetación del sotobosque, situación que varía en aquellos rodales ubicados en la Cordillera de la Costa.

Los rodales evaluados, en términos de área basal residual, muestran que han sido intensamente intervenidos, la mayoría sometidos a extracciones en promedio del $58 \%$ del área basal considerando árboles con diametros superiores a $8 \mathrm{~cm}$ de DAP, en particular los rodales ubicados en la Precordillera de los Andes (Figura $\mathrm{N}^{\circ} \mathrm{N}^{\circ} 3$ ). Por esta causal, los arboles remanentes en los rodales son de diametros delgados y con presencia de individuos sobremaduros distribuidos aisladamente, con claros o huecos en el rodal, y una distribución irregular de los individuos mayoritariamente de origen vegetativo, conformando un bosque de monte medio en estado de latizal.

El diámetro medio de los rodales es de $17 \mathrm{~cm}$, el área basal media es de 15,3 $\mathrm{m}^{2}$ y la densidad de 638 árboles por hectáreas (Cuadro № 4). 
Es frecuente además, apreciar indicios de ramoneo, especialmente de vacunos, que afectan y retrasan el proceso de regeneración de semilla o generativa, o bien que deforman o eliminan los rebrotes que nacen desde los tocones de los árboles que fueron cosechados con fines madereros y en un porcentaje importante para combustible. Junto a los rodales es habitual la presencia de hornillas de carbón que evidencia el uso acual del hualo.

Un analisis de los planes de manejo presentados entre el año 1978 y 2009 para regenerar o intervenir los bosques del Tipo Forestal Roble-Hualo muestra que, en su mayoría los rodales se han intervenido con el método de Corta Selectiva,método que cada vez más se encuentra en desuso debido a la calidad de los bosques ya los diametros disponibles (> $25 \mathrm{~cm}$ ). En general, este tipo de intervención se asemeja a raleo por lo alto o floreo, sin consideración por la regeneración natural y/o la articial ya que esta no se realiza.



Figura $\mathrm{N}^{\circ} 3$

NIVEL DE INTERVENCIÓN DE COSECHA DEL RODAL EN TERMINOS DE AREA BASAL 


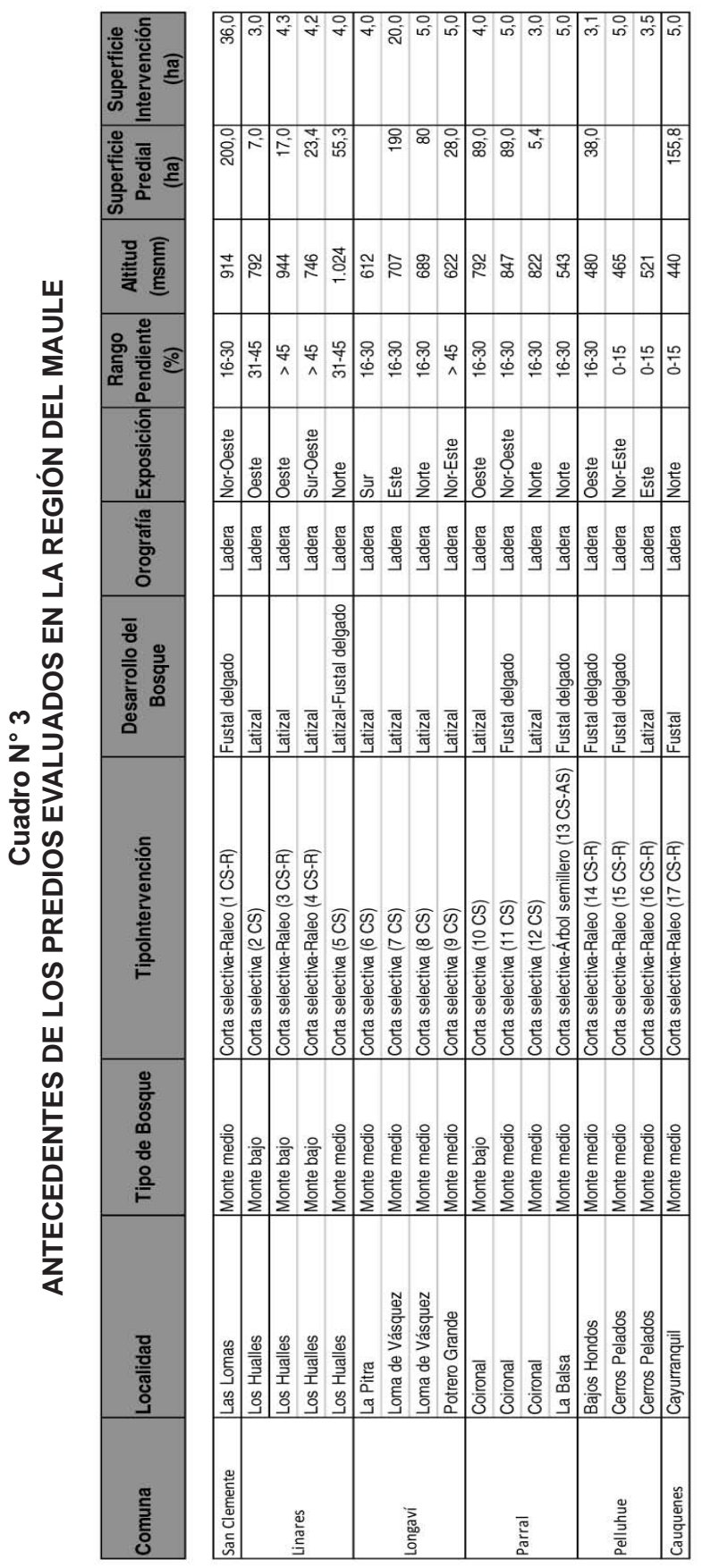




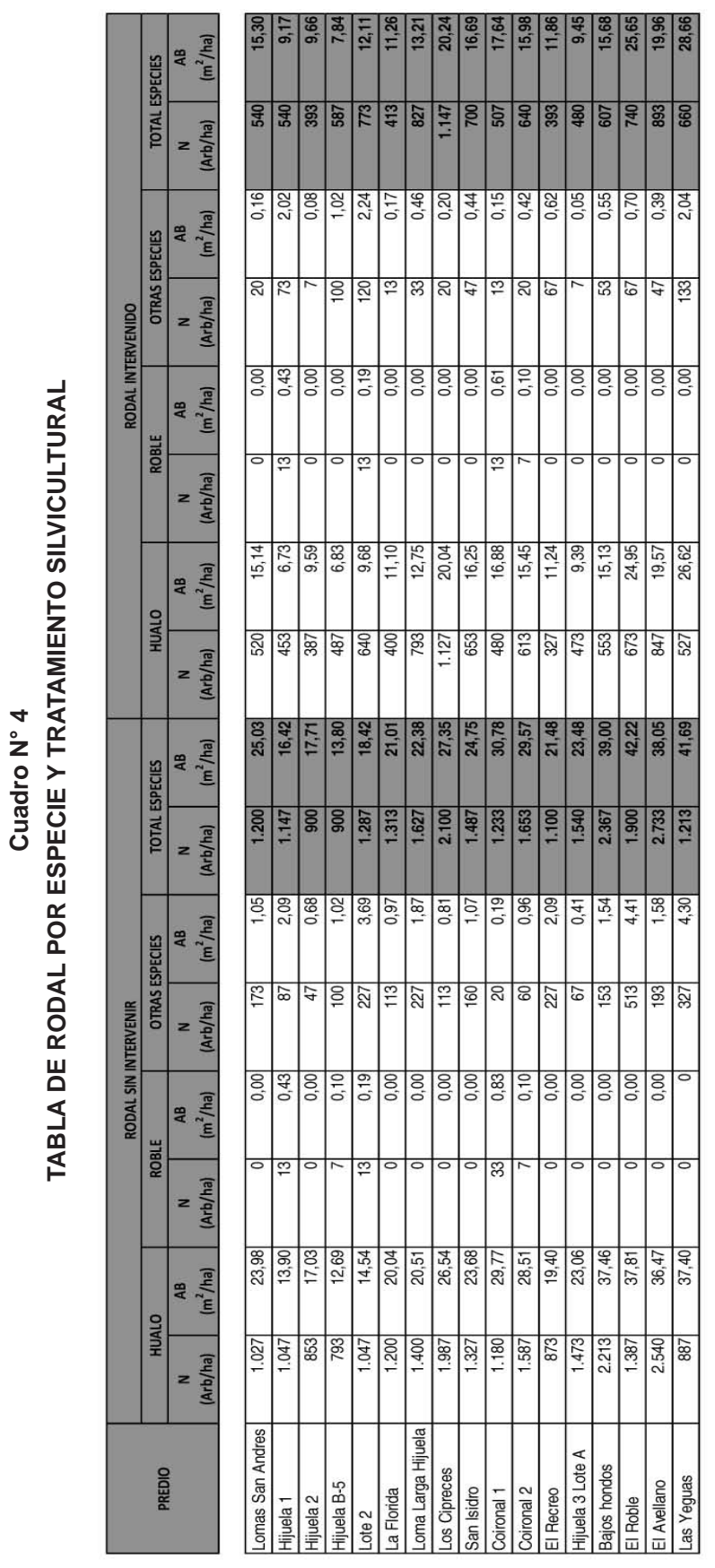



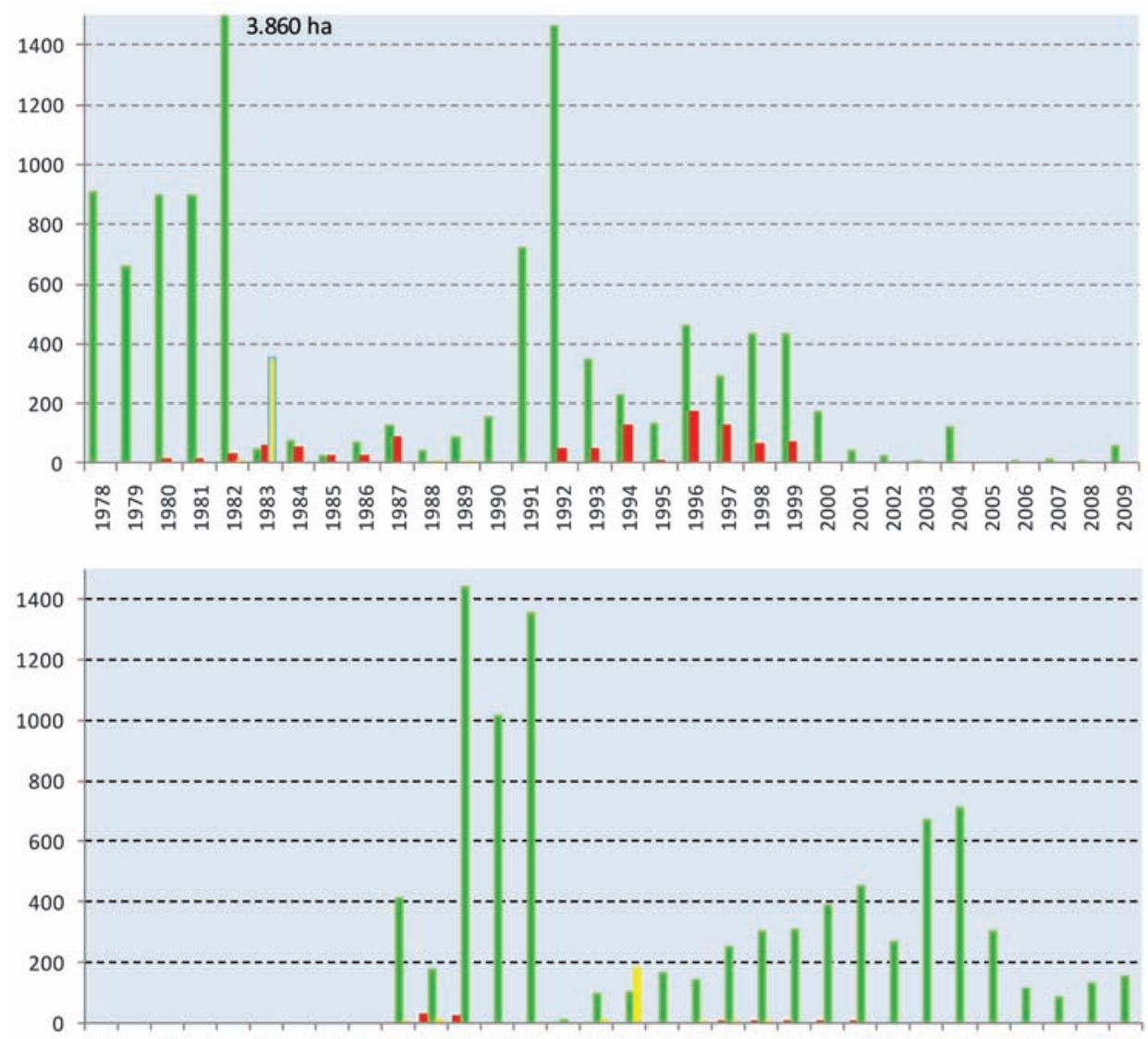

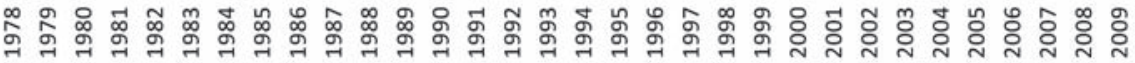

O'higgins

Maule Biobío

Figura $N^{\circ} 4$

SUPERFICIE REGIONAL (ha) DEL TIPO FORESTAL ROBLE - HUALO INTERVENIDA CON CORTAS SELECTIVAS (arriba) Y RALEOS (abajo) DURANTE EL PERIODO 1978-2009

Los rodales que han sido intervenidos dejando un area basal inferior a $15 \mathrm{~m}^{2} / \mathrm{ha}$, presentan escasa regeneracion por semilla y la que existe es procedente de tocones (Figura $\mathrm{N}^{\circ} 5$ ).

La calidad de la troza en los rodales evaluados, fundamentalmente hasta los $4 \mathrm{~m}$ de altura permite que esta pueda ser utilizada como madera aserrada o estructural. Estudios realizados en este tema, indican que la propiedades mecánicas de madera no presentan diferencias estadísticas entre las clases diamétricas (15, 25, 35, y $45 \mathrm{~cm}$ ) (Vásquez y 
Díaz, 2006). La calidad fustal de los árboles remanentes, en general no presentan daños mecánicos, pudriciones, epicornios o ataque de patogenos (Holopterus). En los fustes se detecta la presencia de abundantes ramas verdes especialmente sobre los cuatro metros.
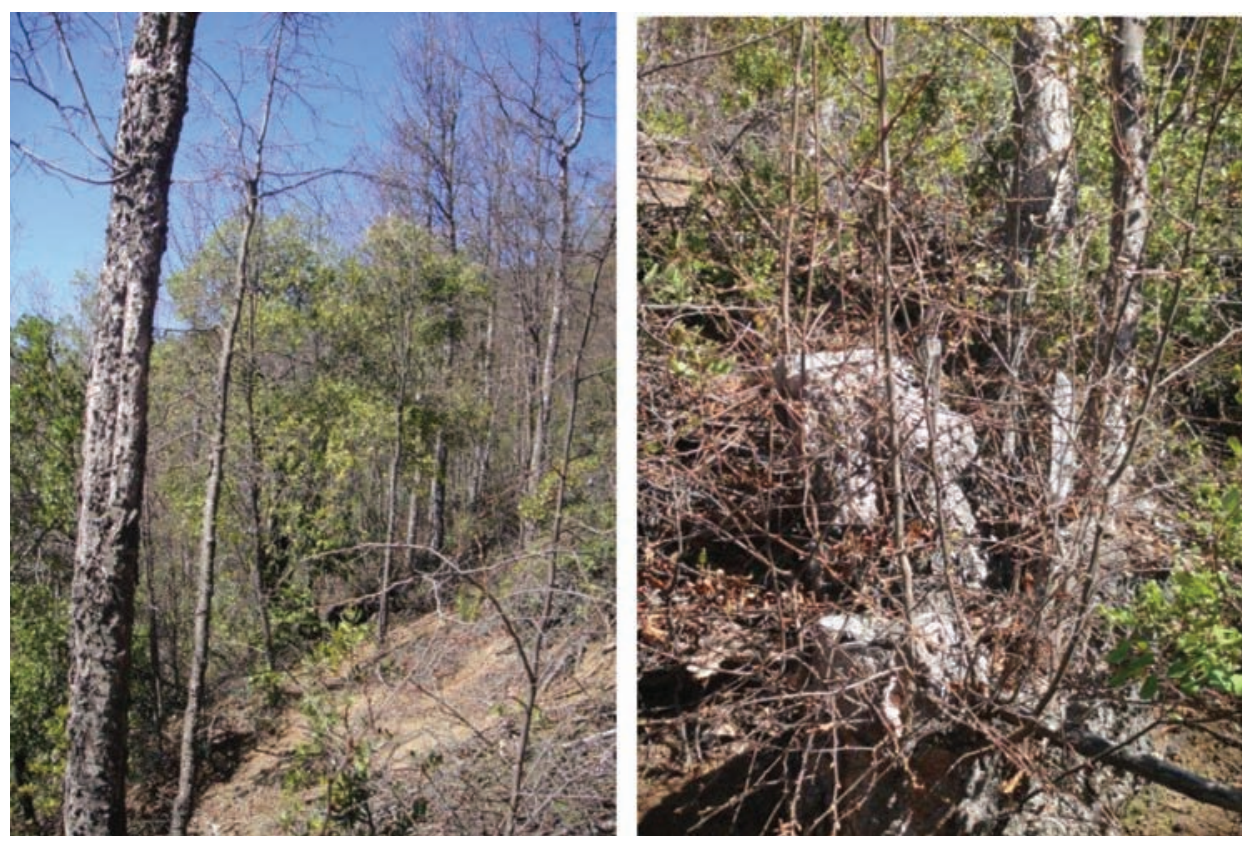

Figura $\mathrm{N}^{\circ} 5$

\section{BOSQUE DE HUALO INTERVENIDO CON EL MÉTODO DE CORTA DE SELECTIVA COMPLEMENTADA CON RALEOS SEGÚN LOS PLANES DE MANEJOS EN LA LOCALIDAD DE LOS HUALLES,LINARES (4 CS -R)}

La regeneración de los rodales se sustenta en la capacidad vegetativa de la especie, ya que una vez cortado los árboles regenera abundantemente de tocón, esto permite cumplir con la exigencia de regenerar más de 3.000 inviduos por hectárea. Como se ha indicado, la mayoría de los predios evaluados utilizan un método de corta selectiva complementado con raleos, extrayendo principalmente los individuos delgados que se desarrollan en los tocones. Estas intervenciones no cumplen con el objetivo de regenerar el bosque o de mejorar la calidad del mismo, ya que no se tiene presente este fin, y en general son cortas que tienen por finalidad proveer materia prima para producir carbón y, ocasionalmente, vigas para estructuras.

Las cortas sin una adecuada planificación generan hoyos de luz (>10 m), que afectan el desarrollo de la regeneración natural, a ello se suma la ditribucion irregular de los árboles, y el tamaño o peso de la semilla que dificulta la dispersión de la misma. Otro factor que afecta la regeneración natural son las sucesivas intervenciones que no permiten a los rodales alcanzar la edad de maduración para la produccion de semillas. 


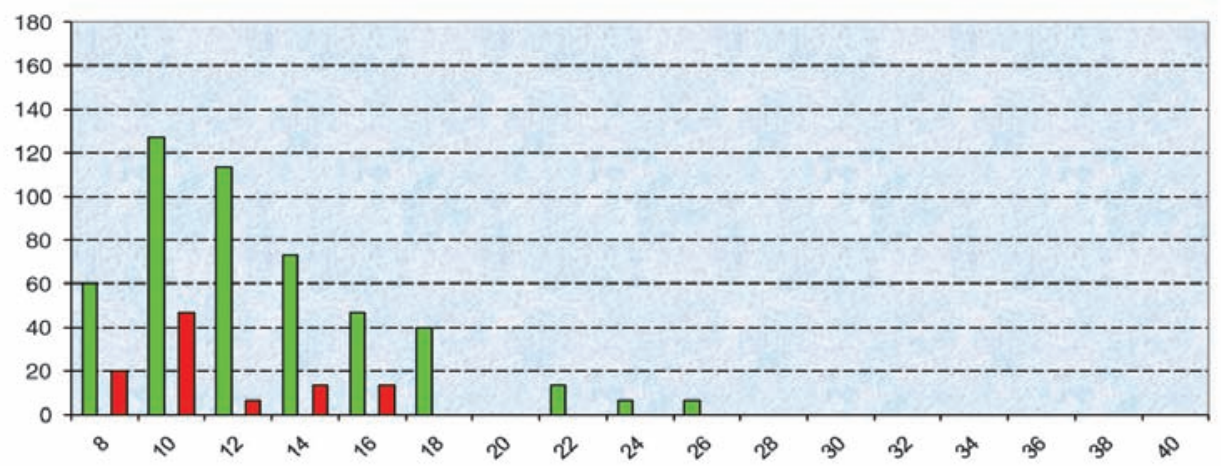

\section{Figura $N^{\circ} 6$ \\ DISTRIBUCIÓN DIAMÉTRICA Y DENSIDAD (arb(ha) SEGÚN CLASE DIAMÉTRICA INTERVENIDA \\ MÉTODO DE CORTA DE SELECTIVA COMPLEMENTADA CON RALEOS LOCALIDAD DE LOS HUALLES,LINARES (4 CS -R).}

Como se ha señalado, la regeneración en gran parte de los rodales es del tipo vegetativa (Cuadro $N^{\circ} 5$ ). La regeneracion de semillas es escasa, afectada por la edad del rodal, además de la abundante presencia de animales que ramonean las plantas y/o consumen las semillas.

La regeneración también se ve afectada por lo tipos de manejos silviculturales, es decir, el objetivo es la cosecha. Se evidencia una extracción irregular que genera espacios que no permiten una adecuada distribución de la semillas, los cuales son colonizados por especies arbustivas y malezas de mayor agresividad, o cuando no ocurre esta situación se encuentran alterados de tal manera que la luz y la temperatura, y por ende la humedad del suelo, no permiten las condiciones para la regeneración natural. 


\section{Cuadro $\mathrm{N}^{\circ} 5$}

\section{TIPO Y CANTIDAD DE REGENERACION NATURAL SEGÚN COMUNA Y TIPO DE} INTERVENCIÓ

\begin{tabular}{|c|c|c|c|c|c|}
\hline \multirow{2}{*}{ Provincia } & \multirow{2}{*}{ Comuna } & \multirow{2}{*}{$\begin{array}{c}\text { Tipo de } \\
\text { Intervención }\end{array}$} & \multirow{2}{*}{$\underset{(p l / h a)}{N}$} & \multicolumn{2}{|c|}{$\begin{array}{l}\text { Tipo de Regeneración } \\
\text { (pl/ha) }\end{array}$} \\
\hline & & & & Vegetativa & Generativa \\
\hline Talca & San Clemente & $1 \mathrm{CS}-\mathrm{R}$ & 0 & 0 & 0 \\
\hline \multirow{12}{*}{ Linares } & \multirow{4}{*}{ Linares } & 2 CS-R & 14.167 & 14.167 & 0 \\
\hline & & $3 \mathrm{CS}$ & 6.667 & 6.667 & 0 \\
\hline & & $4 \mathrm{CS}$ & 0 & 0 & 0 \\
\hline & & 5 CS-R & 0 & 0 & 0 \\
\hline & \multirow{4}{*}{ Longaví } & $6 \mathrm{CS}$ & 0 & 0 & 0 \\
\hline & & $7 \mathrm{CS}$ & 0 & 0 & 0 \\
\hline & & $8 \mathrm{CS}$ & 0 & 0 & 0 \\
\hline & & $9 \mathrm{CS}$ & 5.833 & 5.833 & 0 \\
\hline & \multirow{4}{*}{ Parral } & $10 \mathrm{CS}$ & 5.833 & 5.833 & 0 \\
\hline & & $11 \mathrm{CS}$ & 10.833 & 10.833 & 0 \\
\hline & & 12 CS-AS & 7.500 & 7.500 & 0 \\
\hline & & $13 \mathrm{CS}$ & 0 & 0 & 0 \\
\hline \multirow{4}{*}{ Cauquenes } & \multirow{3}{*}{ Pelluhue } & $14 \mathrm{CS}-\mathrm{R}$ & 10.000 & 10.000 & 0 \\
\hline & & 15 CS-R & 3.333 & 3.333 & 0 \\
\hline & & $16 \mathrm{CS}-\mathrm{R}$ & 2.500 & 2.500 & 0 \\
\hline & Cauquenes & 17 CS-R & 15.833 & 1.667 & 14.167 \\
\hline
\end{tabular}

Uno de los ejemplos donde se presentan buenas características, en cuanto al número de árboles y el área basal, es el rodal ubicado en la Cordillera de la Costa (17 CS $-\mathrm{R}$ ), que se caracteriza por presentar una curva tendiente a la normalidad, si embargo se ha intervenido el rodal en estado secundario, acción que se observa como poco apropiada ya que afecta la calidad del rodal remanente(Figuras $\mathrm{N}^{\circ} 7$ y $\mathrm{N}^{\circ} 8$ ).

El rodal presenta un diámetro y altura promedio de $23 \mathrm{~cm}$ y $16,6 \mathrm{~m}$, respectivamente, un área basal de $28,7 \mathrm{~m}^{2} /$ ha y 660 árboles por hectárea. En estas condiciones se observa una abundante regeneración natural, ello ayudado por la condición de semisombra y la baja presencia de animales. 


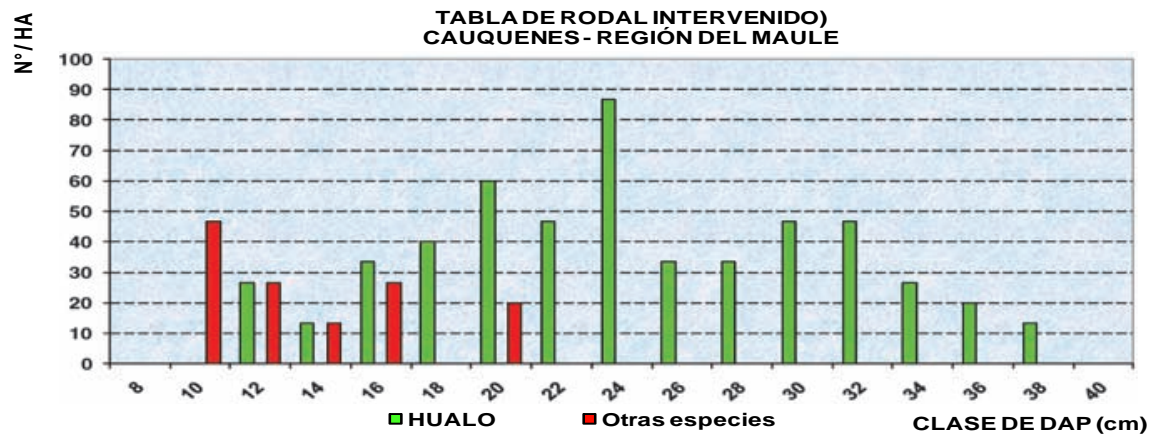

Figura $\mathrm{N}^{\circ} 7$

DISTRIBUCIÓN DIAMETRICA Y DENSIDAD (arb/ha) SEGÚN CLASE DIAMÉTRICA INTERVENIDO

MÉTODO DE CORTA DE SELECTIVA COMPLEMENTADA CON RALEOS CORDILLERA DE LA COSTA CAUQUENES (17 CS -R).

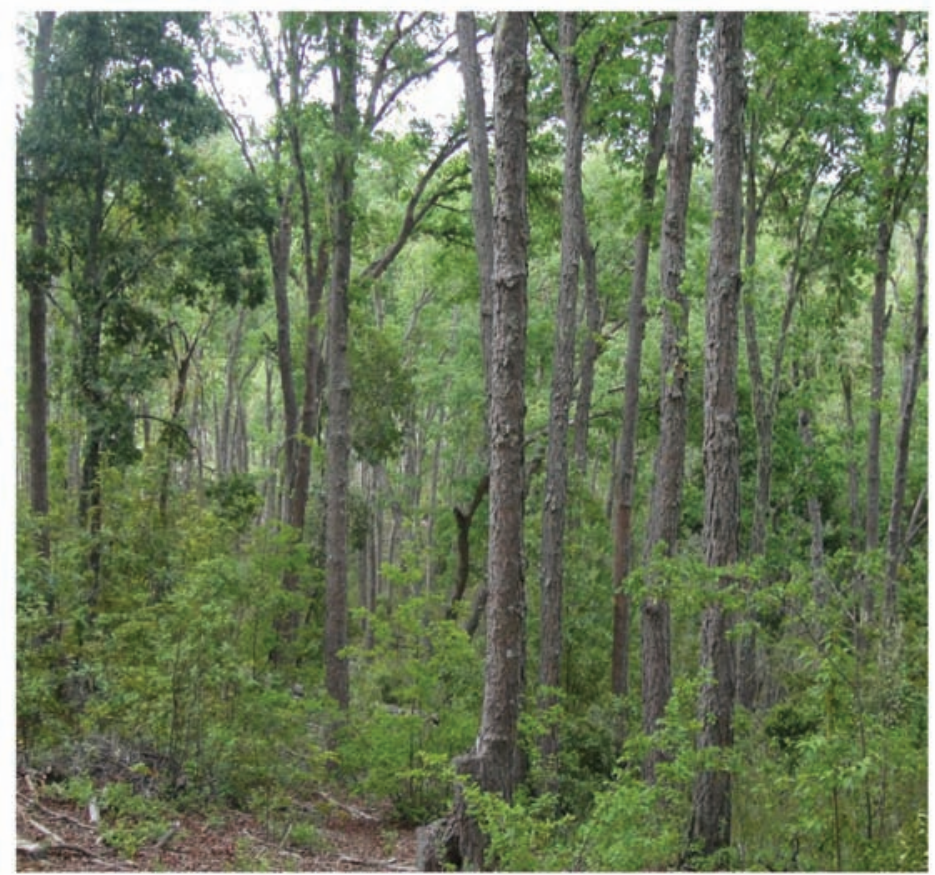

Figura $N^{\circ} 8$

BOSQUE INTERVENIDO DE HUALO UBICADO EN EL SECTOR DE CAYURRANQUI CORDILLERA DE LA COSTA DE CAUQUENES (17 CS-R). 
El método de regeneración de Selección o Corta Selectiva (DS 259/1980), se caracteriza por ser empleado en un rodal donde coexisten individuos de todas las edades y la regeneración se produce constantemente. La forma gráfica de esta expresión es una J invertida, la cual puede tomar a su vez diversas formas (Hawley y Smith, 1972; Smith, 1986; Smith et al., 1997). Es un método para bosques irregulares y conviven como métodos regeneración, raleos y cosechas al mismo tiempo.

El método de Selección complementado con raleos, en la región del Maule, es el método de mayor uso entre los métodos de regeneración (27\%). Fue utilizado intensamente desde el año 1978, alcanzando su máximo en el año 1982, período en el que se intervinieron (corta) en promedio 900 ha anuales. Coincidentemente con lo que ha ocurrido en la actividad forestal, la aplicación del método se redujo a partir el año 2000.

La Tala Rasa como método de regeneración se encuentra permitida en el actual Reglamento Técnico, para los tipos forestales Roble-Hualo y Roble-Raulí-Coigüe. En la Región del Maule, este método fue utilizado en un 1,3\% de toda la superficie intervenida, lo que se intensificó especialmente durante el período comprendido por los años 1989 y 1994. Desde el año 2000, este tipo de intervención prácticamente ha desaparecido como método de cosecha. Lo mismo ha ocurrido con el método de corta del árbol semillero, que se utilizó sólo en cierto número de hectáreas desde el año 1988 hasta el año 1995. Es una práctica que actualmente se encuentra sin uso en el Tipo Forestal Roble - Hualo.

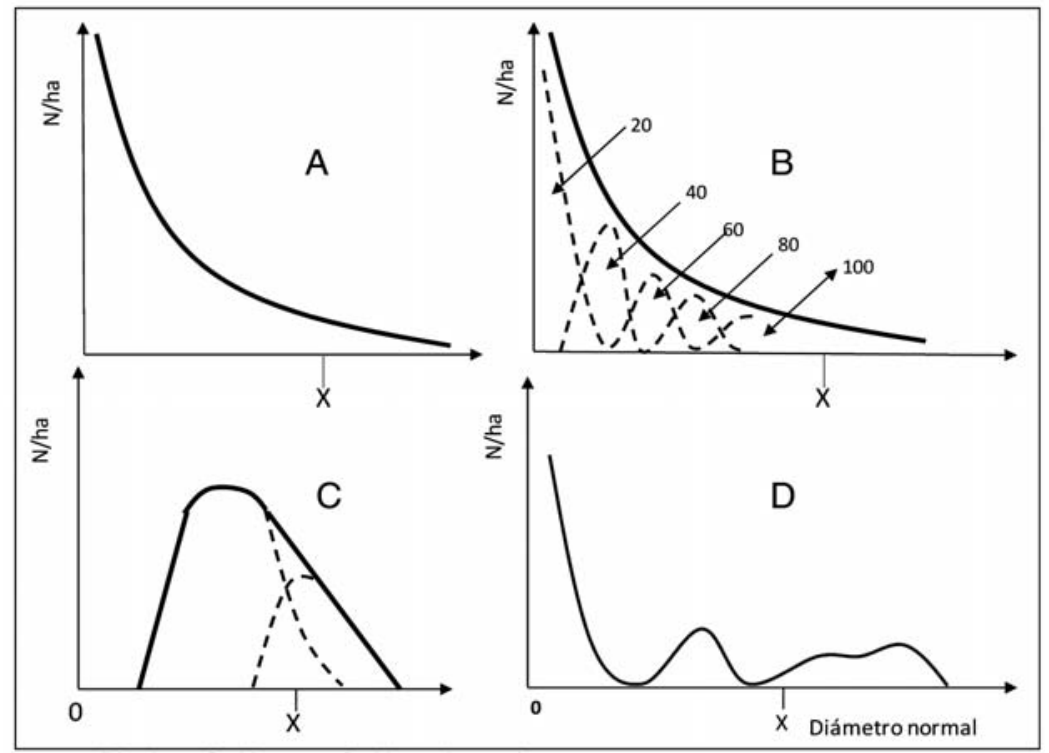

(Hawley y Smith, 1972; Smith et al., 1997)

(Hawley y Smith, 1972; Smith et al., 1997)

Figura $\mathrm{N}^{\circ} 9$

TIPOS DIFERENTES DE DISTRIBUCIÓN DIAMÉTRICA EN BOSQUES IRREGULARES O MULTIETÁNEOS 
El raleo, como tratamiento intermedio, se aplica principalmente en el estado de latizal y fustal delgado del rodal, sin embargo, se extiende tanto hacia el estado de monte bravo como al fustal. El raleo no sólo modifica las características propias del rodal, sino que induce cambios en algunas variables micro-climáticas dentro del mismo, produciendo modificaciones en el sistema bosque.

Los mayoría de los autores, clasifican los raleos en cuatro tipos, los cuales se basan en el desarrollo relativo de las copas (raleo por lo bajo, por lo alto y de selección) y el espaciamiento (raleo mecánico). No obstante, se reconoce un quinto método (raleo libre) que sería una combinación de los cuatro anteriores y que se aplicaría en rodales de estructuras irregulares (Hawley y Smith, 1972; Daniel et al., 1982; Smith, 1986; Rittershofer, 1994; Burschel y Huss, 1997; Smith et al., 1997) como serían los bosques secundarios de Chile (renovales).

Las distintas calificaciones de raleo, se basan en rodales regulares, sin embargo la actual condición de los bosque de Roble-Hualo presenta múltiples variaciones en terreno originadas por la intervenciones pasadas, que han afectado su condición genética, su distribución en terreno y la dinámica de regeneración del bosque, por ello los rodales no deberían estar sujetos a raleos con un esquema fijo de manejo. El estado actual de renovales de Roble-Hualo evaluados, requiere de manejo y una plantación suplementaria, ello queda ratificado en la ley de bosque nativo que incentiva estas prácticas. En este contexto deberían propiciarse en la mayoría de los rodales acciones que se orienten a rejuvenecer el bosque. Los rodales evaluados con menos de $15 \mathrm{~m}^{2} /$ ha y edad inferior a 20 años, no se encuentran en condiciones de regenerar, y cuando ocurre se generan bosques de origen vegetativo.

\section{Cuadro $\mathrm{N}^{\circ} 6$ \\ PORCENTAJE DE INTERVENCIÓN SILVICOLA EN RODALES SEGÚN TIPO FORESTAL DESDE EL AÑO 1978 HASTA EL AÑO 2009}

\begin{tabular}{|l|c|c|}
\hline \multirow{2}{*}{ Tipo de Intervencion } & \multicolumn{2}{|c|}{ Utilización del Método (\%) } \\
\cline { 2 - 3 } & Roble-Hualo * & Roble- Rauli-Coigüe ** \\
\hline Tala Rasa & 1.3 & 2.5 \\
\hline Arbol Semillero & 4.1 & 5.0 \\
\hline Corta de Protección & 11.0 & 2.5 \\
\hline Corta selectiva & 26.6 & 12.0 \\
\hline Raleos & 17.5 & 54.0 \\
\hline Otros & 39.5 & 27.0 \\
\hline
\end{tabular}

* El porcentaje se obtiene en base a 53.359 ha con planes de manejos

de las regiones O'Higgins a Bio Bio.

** El porcentaje se obtiene en base a 206.680 ha con planes de manejos de las regiones de Biobío y La Araucanía. 
En cuanto a los métodos de regeneración, estos pueden definirse de la siguiente manera (Hawley y Smith, 1972, Daniel at al.,1982; Garrido 1981; Smith, et al., 1997; Cruz y Schmidt, 2007):

Monte Alto: Regeneración a partir de semilla

\author{
Bosques Regulares \\ Método de Tala Rasa \\ Método de Árbol Semillero \\ Método de Cortas Sucesivas o de Protección \\ Bosques Irregulares \\ Método de Selección
}

Monte Bajo: Regeneración a partir de cepas (retoño de tocón).

Monte Medio: Regeneración a partir de semillas y cepas

En Chile, se han aplicado tanto para bosques regulares como irregulares sólo los métodos de monte alto (GTZ-CONAF, 1998), aunque no se distingue claramente si se aplican en función de su estado de desarrollo o condición del bosque. Antecedentes bibliográficos indican una tendencia de selección de métodos en base a condiciones de pendiente del terreno y a estructura volumétrica del rodal a intervenir.

Los resultados obtenidos con los métodos de Tala Rasa y Árbol Semillero, en general, no han sido exitosos en materia de regeneración, especialmente en las regiones del Maule, Biobio y La Araucanía y, cuando regeneran, lo hacen nuevamente de tocón. Las razones para esta respuesta obedecen a características ambientales restrictivas, tecnicas y tipo de plantas utilizadas en la regeneración artificial y la regeneración natural se ha visto afectada por la periodicidad de semillación, de las especies consideradas en los tipos forestales en que se permite la utilización de dichos métodos (Donoso, 1981; Donoso, 1994; Donoso y Lara, 1999).

El método del Árbol Semillero, en Chile y de acuerdo a los actuales técnicas de manejo, no jugaría un rol en la actividad silvícola, especialmente en Roble-Hualo, situación similar ocurre en otras lalitudes (Hawley y Smith, 1972; Daniel at al., 1982; Smith et al., 1997). El método de Árbol Semillero ha demostrado que es aplicable sólo en condiciones particulares y requiere de un proceso de intervención moderada. La fructificación irregular de los Nothofagus complica de sobremanera la utilización de este método, en particular cuando suceden años de fructificación deficiente y se posibilita el ingreso de malezas (Chusquea spp, Rubus sp, Carduus sp, gramíneas, otras) que posteriormente no permiten el establecimiento de la especie deseada.

Las malezas son un problema cada vez más importante en la dinámica de los bosques. Cifras sobre su presencia indican que en Chile, en el año 1526 existían 128 especies consideradas como malezas y sólo entre 1974 y 1991 se incorporaron 100 
nuevas especies más; al año 1992 se han contabilizado un total de 600 diferentes especies (Mathei, 1995). Este tipo de vegetación encuentra en los ecosistemas del bosque nativo un favorable ambiente para desarrollarse y colonizar áreas expuestas, en particular aquellas resultantes de la aplicación de los métodos de Tala Rasa y Árbol Semillero.

Especialistas como Burschel et al. (1991) han indicado que a nivel nacional la Corta del Árbol Semillero, desde el punto de vista ecológico, no se distingue de la Corta de Tala Rasa, ya que no tiene en consideración las características ecológicas y las particularidades locales del tipo forestal. Si bien es una alternativa, los productores por razones de operatividad y de mercado, utilizan el método que ofrezca menor complejidad y mayores ingresos, sin tener muchas veces la preocupación de su sustentabilidad.

El "floreo" es una práctica que se ha utilizado en forma histórica en los bosques chilenos y que actualmente sigue operando en la mayoría de los predios, en particular en la pequeña propiedad y en algunas empresas que utilizaron el bosque para la producción de astillas en la década del 1985 a 1995. Esta práctica extrae y extrajo lo mejores individuos de las especies de valor maderero, quedando un dosel raleado, compuesto de individuos no deseados (por ejemplo árboles parcialmente muertos, brinzales, o especies sin valor comercial). Esta práctica, de uso frecuente en los bosques clasificados según su estructura como bosques adultos y bosques secundarios (renovales), tiene un alto impacto en la calidad del recurso, ya que elimina los mejores individuos.

Para mantener la productividad de los bosques en su calidad maderera y de sus productos no madereros, se deben realizar modificaciones en la forma que se están aplicando los métodos de regeneración y los tratamientos intermedios, para lograr un equilibrio entre los objetivos de conservación biológica y manejo productivo de los bosques (Armesto et al., 1999).

Existen autores que han planteado la necesidad de modificar los actuales métodos de regeneración con una propuesta que apunte a dejar como únicos métodos la Corta Selectiva y la Corta de Protección (Cruz y Schmidt, 2007). Otra alternativa es la utilización de un método desarrollado en Norteamérica denominado sistema de cosecha de retención variable, el cual considera un intervalo continuo de niveles de cosecha y mantención de elementos estructurales del dosel en un área definida, es decir, el sistema busca mantener rodales mixtos, con coexistencias de parches coetáneos y mutietáneos (Armesto et al., 1999).

Las intervenciones silviculturales en el marco de un manejo forestal sustentable se asimilan en cierta manera al desarrollo del ecosistema natural (Cruz y Schmidt, 2007), lo que implica aprovechar y mantener la capacidad de autorregulación de los bosques y por ello se plantean como manejo del bosque nativo dos tramientos silviculturales: Corta Selectiva y Corta de Protección, teniendo en consideración los tipos forestales, estructura de manejo de existencias, rotación y ciclos de corta (Cuadro $\mathrm{N}^{\circ} 7$ ). 
Cuadro $\mathrm{N}^{\circ} 7$

\section{SISTEMAS DE REGENERACIÓN PROPUESTOS Y RESULTADOS ESPERADOS, SEGÚN TIPO FORESTAL}

\begin{tabular}{|c|c|c|c|c|c|c|}
\hline \multicolumn{2}{|c|}{ Bosque Natural } & \multicolumn{5}{|c|}{ Bosque Maduro } \\
\hline Tipo Forestal & $\begin{array}{c}\text { Existencias } \\
\text { Volumen } \\
\text { Bruto } \\
\text { (m3/ha) }\end{array}$ & $\begin{array}{l}\text { Estructura } \\
\text { de Manejo }\end{array}$ & $\begin{array}{l}\text { Tratamiento } \\
\text { Silvicultural }\end{array}$ & $\begin{array}{c}\text { Crecimiento } \\
\text { Esperado } \\
\text { Volumen } \\
\text { Bruto } \\
\text { (m3/ha/año) }\end{array}$ & $\begin{array}{l}\text { Rotación } \\
\text { (Años) }\end{array}$ & $\begin{array}{l}\text { Ciclo } \\
\text { Corta } \\
\text { (Años) }\end{array}$ \\
\hline Alerce & 1.000 a 2.000 & MAI & Corta Selectiva & $1-4$ & -- & $20-40$ \\
\hline $\begin{array}{l}\text { Ciprés de las } \\
\text { Güaitecas }\end{array}$ & $50-300$ & MAI & Corta Selectiva & $0,3-1$ & -- & $20-40$ \\
\hline Araucaria & $800-1.500$ & MAI & Corta Selectiva & $2-6$ & -- & $20-40$ \\
\hline $\begin{array}{c}\text { Ciprés de la } \\
\text { cordillera }\end{array}$ & $100-400$ & MAI & Corta Protección & $1-6$ & -- & $20-30$ \\
\hline Lenga & $400-700$ & MAR & Corta Protección & $4-6$ & $120-160$ & $120-150$ \\
\hline $\begin{array}{l}\text { Coigüe de } \\
\text { Magallanes }\end{array}$ & $400-700$ & MAR & Corta Protección & $4-6$ & $120-160$ & $120-150$ \\
\hline Roble-Hualo & $200-400$ & MAR/MBR & Corta Protección & $4-6$ & $100-120$ & $120-120$ \\
\hline $\begin{array}{l}\text { Roble-Raulí- } \\
\text { Coigüe }\end{array}$ & $200-600$ & MAR & Corta Protección & $6-12$ & $80-120$ & $80-120$ \\
\hline $\begin{array}{l}\text { Coigüe-Raulí- } \\
\text { Tepa }\end{array}$ & $600-1200$ & MAR & Corta Protección & $6-12$ & $80-150$ & $80-150$ \\
\hline Esclerófilo & $100-200$ & $\begin{array}{l}\mathrm{MAl} / \mathrm{MAR} / \\
\mathrm{MB} / \mathrm{MN}\end{array}$ & $\begin{array}{l}\text { Corta Selectiva } \\
\text { Corta Protección }\end{array}$ & $0,5-5$ & $20-60$ & $15-30$ \\
\hline $\begin{array}{l}\text { Siempre } \\
\text { verde }\end{array}$ & $300-600$ & $\begin{array}{l}\text { MAR/MAI/ } \\
\text { MN }\end{array}$ & $\begin{array}{l}\text { Corta Selectiva } \\
\text { Corta Protección }\end{array}$ & $2-6$ & ¿? & ¿? \\
\hline $\begin{array}{l}\text { Palma } \\
\text { chilena }\end{array}$ & --- & MAI & $\begin{array}{l}\text { Corta Selectiva } \\
\text { Corta Protección }\end{array}$ & -- & -- & ¿? \\
\hline
\end{tabular}

(Fuente: Cruz y Schmidt, 2007).

MAI: Monte Alto Regular

MAR: Monte Bajo

MM: Monte Medio
-- : No corresponde

¿?: Variable según subtipo, especie y tipo de producto. 

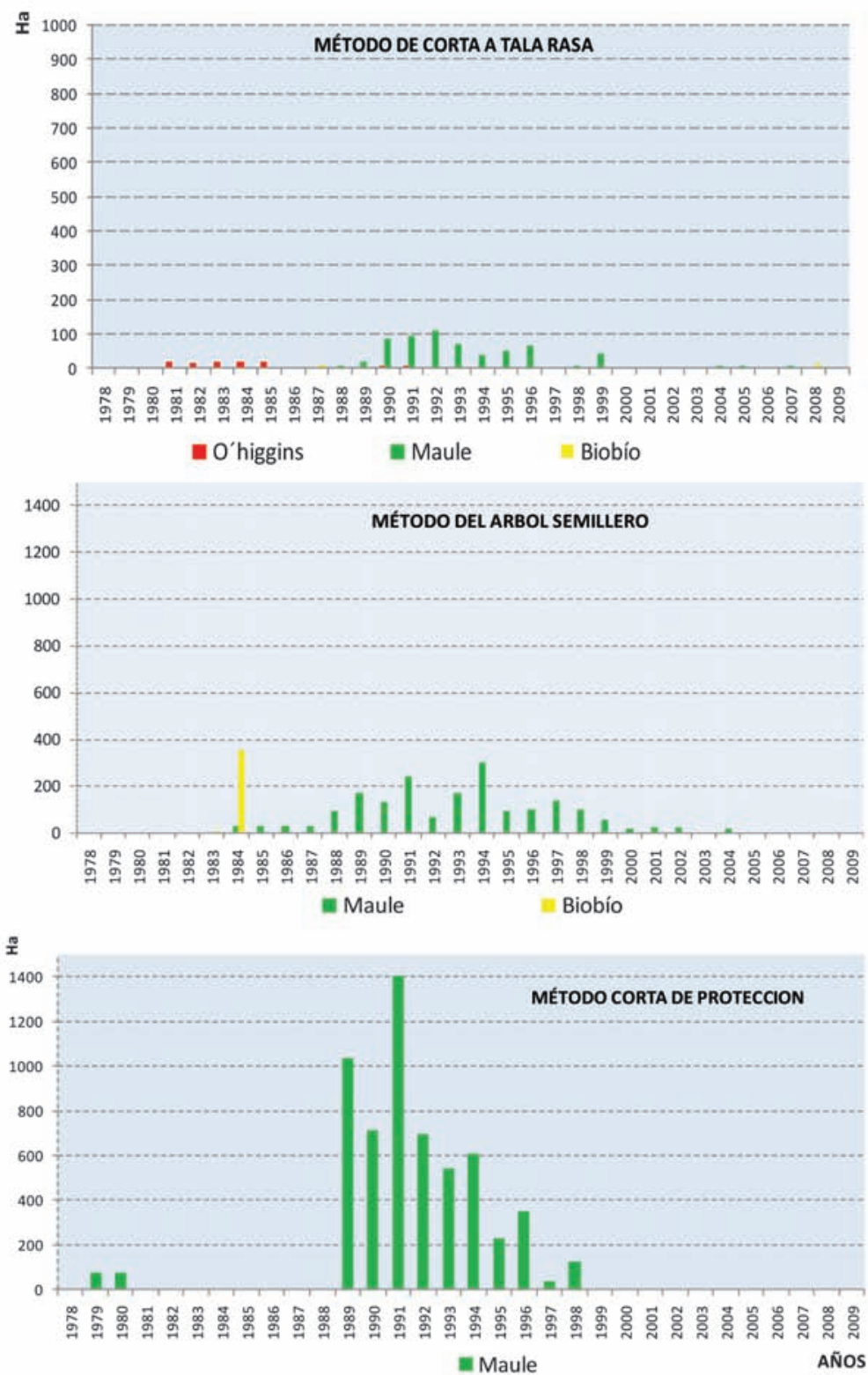

Figura $\mathrm{N}^{\circ} 10$

SUPERFICIE REGIONAL DEL TIPO FORESTAL ROBLE - HUALO INTERVENIDA CON LOS MÉTODOS TALA RASA (ARRIBA), ARBOL SEMILLERO (CENTRO) Y PROTECCIÓN (ABAJO) DURANTE EL PERIODO 1978-2009 
El resultado de un método de regeneración depende no tanto del método a utilizar, sino de cómo se aplica. Este debiera considerar las relaciones ambientales y la dinámica de crecimiento de las especies, transformándose en la base para una apropiada definición legal y una tipología forestal que, en la actualidad, no representa las diversas situaciones del bosque nativo. En este sentido Burschel et al. (1991) indican que las normas o métodos no pueden ser de uso generalizado en sus valores límites, especialmente para un país con las dimensiones latitudinales de Chile. Indican también que resulta mucho más operativo fijar criterios generales y hacer las precisiones localmente a dichos criterios.

Estos autores plantean la necesidad de definir criterios ecológicos o silvícolas para emplear una determinada opción silvícola, es decir, no deben quedar sujetos a una definición general, ya sea en base a un determinado método o definición del tipo forestal. La mayoría de los bosques evaluados por este estudio mostraron una alta variabilidad que dificulta proponer un determinado método de regeneración o intervención.

Ante este escenario de variabilidad, se puede dar la situación de intervenir el rodal para favorecer la regeneración natural o artificial, aplicar cortas intermedias o bien actividades de cosecha de árboles individuales.

Para adaptarse a estos múltiples mosaicos de situaciones, se deben generar los mecanismos administrativos que permitan tal diversidad de intervenciones (Rothermel, 2000). Lo anterior exige una activa participación del Estado a través de sus instituciones y por cierto del sector de los productores privados interesados en lograr la sustentabilidad del recurso bosque nativo.

En el mismo sentido, se debe dejar de lado los sistemas esquemáticos y privilegiar criterios que reflejen la sustentabilidad de los mismos. Así, Burschel et al. (1991) plantean por ejemplo los siguientes criterios:

La capacidad de carga o sustentación.

El umbral de extinción del ecosistema (bosque).

La velocidad de regeneración del ecosistema (bosque).

Se puede mencionar por lo tanto, que los indicadores deben ser definidos de modo de reflejar las particularidades regionales y/o locales del bosque nativo a intervenir. Más allá de actualizar o definir los métodos de regeneración y vincularse específicamente con una tipología forestal, como lo establece la Ley de Bosque Nativo, estos deben ser una guía de la capacidad ecológica del bosque o una ayuda para evitar situaciones anómalas que pueden degradar el ecosistema. Por ejemplo, se establecen plantas de raulí como especie principal en rodales tipificados como siempreverde, o se producen plantas con semillas provenientes de ambientes climáticos diferentes, en tal sentido INFOR esta avanzado en generar el primer Reglamento de semillas y plantas forestales del país.

En Chile, la mayoría de los bosques corresponden a formaciones secundarias fuertemente intervenidas, con diferentes estructuras verticales y composición de especies, afectadas por la actividad ganadera, la lejanía a los centros de consumo y los caminos 
forestales, condiciones que hoy día influyen en la selección de los métodos silvícolas a aplicar.

De lo expuesto, se desprende que se requiere introducir variaciones a los métodos de regeneración que se utilizan, como lo son las transformaciones de bosque a través de Cortas Selectivas y la aplicación de raleos denominados libres o de selección, en aquellas áreas factibles de transformar y que estén clasificadas como bosque nativo.

\section{CONSIDERACIONES FINALES}

Tanto la literatura nacional (Garrido, 1981; Vita, 1996; Espinosa y Muñoz, 2000) como la internacional (Hawley y Smith, 1972; Mayer, 1992; Nyland, 1996), muestran procedimientos silviculturales que son utilizados en bosques de estructura simple (número de especies) y equilibrados. Sin embargo, en Chile predominan bosques naturales que se caracterizan por su alta heterogeneidad, en cuanto a la distribución, calidad de los individuos, y su estructura compleja (riqueza de especies), y por haber sido intervenidos sin consideraciones de tipo silvícola generando masas boscosas que requieren variados métodos silviculturales para lograr su equilibrio, en términos de estructura vegetacional y de calidad maderera y no maderera ( hongos comestibles, frutos, otros). Estos bosques, requieren ser transformados en bosques con valor comercial y para ello se debe:

Enriquecer con especies de interés económico.

Aplicar cortas intermedias (cortas de mejoramiento, sanitarias, raleos, otras).

En los bosques adultos, reducción adecuada de la densidad para fomentar las especies de interés económico.

Para alcanzar estos objetivos existen dos posibilidades:

Transformación directa, que es el cambio del bosque existente por un bosque con especies de interés comercial.

Transformación indirecta, que es la aplicación de medidas apropiadas para encauzar el desarrollo del bosque existente y que tiende paulatinamente hacia un bosque comercial (Samek, 1974).

En los primeros, bosques con especies de interés económico, se debe determinar si se realiza transformación indirecta (corta de mejora) o transformación directa. La indirecta resulta compleja por su carácter de largo plazo, motivo por el cual donde se presenten condiciones favorables puede resultar más económica la transformación directa que consiste en la cosecha del bosque existente y la repoblación artificial del área, la que puede realizarse bajo cobertura o en Tala Rasa en Fajas. Se debe tener en consideración que, la aplicación de este método dependerá además de la condición ambiental donde se ubique el rodal. 
Los métodos de regeneración aplicados al bosque nativo chileno no se adecúan a las múltiples opciones de manejo. Se adaptan de mejor forma los métodos de regeneración desarrollados para los bosques tropicales o bosques de estructura compleja (Samek, 1974; Lamprecht, 1986). Entre estos métodos se mencionan las cortas de mejora, las cortas sucesivas tropicales y el enriquecimiento.

El estado actual del bosque nativo, sea adulto o secundario (renovales), las características de la propiedad y la infraestructura caminera son factores que condicionan el tipo de intervención y las particularidades del método silvicultural (Quiroz, 1998). La alta variabilidad de situaciones de sitio (clima y suelo), la heterogeneidad del bosque en cuanto a desarrollo y la composición de especies, determinan que en un rodal específico se deben aplicar diferentes tratamientos silviculturales, ya sea método de regeneración, cortas intermedias o enriquecimiento.

Sin embargo, la actual reglamentación (DS 259/1980) no se adecúa a la diversidad de situaciones del bosque. Los tipos forestales y los diferentes métodos de regeneración definidos en este decreto son rígidos y no se adaptan a los bosques que se encuentran en desequilibrio productivo. Es decir, la caracterización de un rodal determinado, en base a una clasificación de ecosistemas forestales o tipo forestales, debe considerarse como un indicador del potencial productivo a lograr para una especie o grupo de especies. Asimismo, los métodos de regeneración, tal como lo indica el Reglamento, no contribuyen al objetivo planteado debido a que dichos modelos deben ser aplicados en bosques en equilibrio o en régimen de manejo. La Ley de Bosque Nativo (Ley 20.283) recoge la necesidad de actualización de los tipos forestales y de los métodos de regeneración, pero ésta no debe basarse en un modelo esquematizado como el aplicado durante los últimos 35 años.

En definitiva, se plantea la necesidad de definir criterios y no esquemas de intervención, de modo de lograr adecuarse a las múltiples opciones de manejo posibles de aplicar en el bosque nativo, por lo tanto se requiere, además, de una adecuación del sistema administrativo del Estado en la gestión y en el sistema de incentivos, entre otros aspectos.

\section{REFERENCIAS}

Armesto, J.; F. Franklin; K. Kalin y C. Smith-Ramírez, 1999. El sistema de cosecha con "retención variable": una alternativa de manejo para conciliar los objetivos de conservación y producción en los bosques nativos chilenos. En: Donoso, C. y A. Lara (ed.). Silvicultura de los boques nativos de Chile. Editorial Universitaria. Santiago, Chile. p:69-94.

Burschel, P. y J. Huss, 1997. Grundiss des Waldbaus. 2, neubearbeitete und erweitere Auflage. Parey Studientexte 49. Berlin. 487p.

Burschel, P.; J. Edens y J. Morello, 1991. Política de explotación del bosque nativo. Programa de Cooperación Técnica. FAO, Santiago. 115p.

CONAF, 2010. Gerencia de Normativas y Fiscalización de la Corporación Nacional 
Forestal (base de datos).

CONAF, 2010a. Ley sobre Recuperación del Bosque Nativo y Fomento Forestal y sus Reglamentos. Ley Número 20.283. Corporación Nacional Forestal. 79 p.

CONAF, 2010b. Gerencia de Normativas y Fiscalización de la Corporación Nacional Forestal (base de datos).

CONAF-CONAMA-BIRF, 1999. Catastro y Evaluación de Recursos Vegetacionales Nativos de Chile. Informe Nacional con Variables Ambientales. Corporación Nacional Forestal-Comisión Nacional del Medio Ambiente-Banco Internacional de Reconstrucción y Fomento. Santiago. 90 p.

Cruz, G. y H. Schmidt, 2007. Silvicultura en bosques nativos. En: Hernández, J.; C.L. de La Maza y C. Estades (eds.). Biodiversidad: Manejo y conservación de recursos forestales. Universidad de Chile. Editorial Universitaria. Santiago. 279-307p.

Daniel, T. W.; J.A. Helms y F.S. Baker, 1982. Principios de silvicultura. 2nd edn. McGrawHill. Mexico. 492p.

Donoso, C., 1981. Tipos Forestales de los bosques nativos de Chile. Investigación y Desarrollo Forestal. Documento de Trabajo № 38. CONAF-FAO-PNUD. Santiago. 70p.

Donoso, C., 1994. Bosques Templados de Chile y Argentina: Variación, estructura y dinámica. Editorial Universitaria. Santiago. Chile. 484 p.

Donoso, C. y A. Lara (ed.), 1999. Silvicultura de los bosques nativos de Chile. Editorial Universitaria. Santiago. 421p.

Espinosa, M. y F. Muñoz, 2000. Silvicultura aplicada. Apuntes de clases. Fac. de Cs. Forestales. Departamento de Silvicultura. Concepción, Chile.

FIA, 2001. Bosque Nativo en Chile: Situación actual y Perspectivas. Estudios para la Innovación. Fundación para la Innovación Agraria FIA-Ministerio de Agricultura. Santiago. $113 p$.

Garrido, F., 1981. Los sistemas silviculturales aplicables a los bosques nativos chilenos. Santiago, Chile. FAO:DP/CHI/76/003. Documento de Trabajo № 39. 110p.

GTZ-CONAF, 1998. Experiencia silvicultural del bosque nativo de Chile. Recopilación de antecedentes para 57 especies arbóreas y evaluación de prácticas silviculturales. Deutsche Gesellschaft für Technische Zusammenarbeit-Corporación Nacional Forestal. Santiago. 420p.

Hawley, R. y D. Smith, 1972. Silvicultura práctica. (Omega). Barcelona. 544p.

INFOR, 2009. Anuario Forestal 2008. Boletín Estadístico 121. Instituto Forestal. Santiago. 161 p. 
Lamprecht, H., 1986. Waldbau in den Tropen. Editorial Paul Parey. Hamburg und Berlin. $318 \mathrm{p}$.

Mathei, O., 1995. Manual de Malezas que crecen en Chile. Universidad de Concepción.545p.

Mayer, H., 1992. Waldbau auf soziologisch-ökologischer Grundlage. 4. Neu Bearbeitete Auflage. Stuttgart. 522p.

Nyland, R. D., 1996. Silviculture, Concepts and Applications. The McGraw-Hill Companies, Inc. New York. 633p.

Quiroz, I., 1998. Untersuchugen zur waldbaulichen Behandlung von NothofagusPrimär-und Sekundärwäldern in den Anden der IX. und X. Region Chiles. Diss. Forstwissenschaftlichen Facultät der Ludwig-Maximilians-Universität München. Freising. $171 \mathrm{p}$.

Quiroz, I.; E. García; M. González; A. Lucero; A, Villarroel y H. Soto, 2010. Evaluación y análisis de los métodos regeneración aplicados en el tipo forestal RO-RA-CO de la Precordillera de los Andes de las Regiones del Biobío y la Araucanía.104 p.

Rittershofer, F., 1994. Waldpflege und Waldbau - für Studierende und Praktiker. 1. Auflage. Freising: Rittershofer Verlag. 481 p.

Rothermel, H., 2000. Manejo Sustentable de Bosque Nativo. Una perspectiva económica. Documento técnico. DED. Serie de documentos. Experiencias de Cooperación N 16/00. Santiago. 114p.

Samek, V., 1974. Elementos de silvicultura de los bosques latifolios. La Habana. 291p.

Smith, D. M.; B. C. Larson; M. J. Kelty y P. M. Ashton, 1997. The practice of silviculture. Applied forest ecology. Nine edition. Ed. John Wiley and Sons. New York. 537p.

Smith, D. M., 1986. The Practice of Silviculture. Eighth edition. Ed. John Wiley and Sons. New York, NY. 527p.

Vásquez, M. y Díaz, P., 2006. Caracterización física y Mecánica de la madera de la especie Nothofagus glauca Proveniente de la Zona de Cauquenes, VII Región.

VITA, A., 1996. Los tratamientos silviculturales. Fac. de Cs. Agrarias y forestales. Esc. de Cs. Forestales. Santiago Chile.

ZÖHRER, F., 1980. Forstinventur. Ein Leitfaden für Studium und Praxis. Verlag Paul Parey, Hamburg und Berlin, Germany. 207p.

N 
